\section{Antidepressants' cellular target}

Certain antidepressant drugs seem to work by acting on a tiny population of brain cells in the cortex. Identifying the specific cells targeted by these drugs, which are known as serotonin-specific reuptake inhibitors (SSRIs), could aid the development of more selective medicines.

Nathaniel Heintz and his team at the Rockefeller University in New York homed in on a group of cortical neurons that express a protein called p11 - levels of which are decreased in depression. This protein regulates the signalling of the transmitter serotonin in the brain.

Mice that were treated longterm with the SSRI fluoxetine showed alterations in the expression of many genes in p11-producing cortical neurons, but not in neurons that lacked p11. When the researchers deleted the gene that encodes p 11 from cortical neurons, the mice no longer responded to the SSRI in behavioural tests that model aspects of depression.

Cell 149, 1152-1163 (2012)

\section{CANCER}

\section{Forcing cells to divide}

Aggressive breast cancers dubbed 'triple negative' could one day be treated by inhibiting a protein that helps to control the initiation of mitosis - the segregation of copies of DNA strands that precedes cell division.

The growth of these tumours depends on the protein WEE1, which prevents cells from entering mitosis too early. Nicholas Turner at the Institute of Cancer Research in London and his team treated cultured breast cancer cells with an experimental drug that inhibits WEE1, and an approved therapy, gemcitabine, that prevents new DNA from being made. The combined treatment sent cells into mitosis before they had finished copying their DNA, eventually triggering programmed cell death.

The treatment also induced early mitosis in human colon cancer cells that had been implanted into mice, and caused the tumours to grow more slowly than did treatment with either drug alone.

Cancer Discov. http://dx.doi. org/10.1158/2159-8290.CD-110320 (2012)

\section{GLACIOLOGY}

\section{Greenland glacier map}

Satellite observations made during the International Polar Year 2008-09 have yielded a near-complete map of ice motion in Greenland.

Eric Rignot and Jeremie Mouginot of the University of California, Irvine, combined radar data from three satellites to map the velocities of the island's largest glaciers at high resolution. The speed at which Greenland's glaciers are moving towards the coast ranges from just a few centimetres per year to 13 kilometres per year for the fastest-moving ice stream, Jakobshavn Isbræ. Glaciers in areas with high annual precipitation are generally moving faster than those in Greenland's dry and cold north.

The map provides a new constraint for ice-sheet models, the authors say. Geophys. Res. Lett. http://dx.doi. org/10.1029/2012GL051634 (2012)

\section{VASCULAR BIOLOGY}

\section{Stem cells from blood vessels}

The development of certain vascular diseases involves the division and migration of blood vessel cells. These seem to arise from stem cells in the vessel wall, not from smooth muscle cells as previously thought.

Song Li at the University of California, Berkeley, and his team isolated the stem cells from rat, mouse and human

COMMUNITY CHOICE

The most viewed papers in science

\title{
With stress comes inflammation
}

\section{HIGHLY READ \\ on www.pnas.org in April}

University in Pittsburgh, Pennsylvania, and his team quarantined 276 volunteers and then exposed them to a rhinovirus that causes the common cold. People who had recently been experiencing a threatening stressful event were more likely to develop a cold than those who had not experienced stress. In the stressed individuals, white blood cell numbers did not correlate with levels of the hormone cortisol - indicating that the cells were insensitive to cortisol's anti-inflammatory effect.

In another study of 79 volunteers exposed to a rhinovirus, those with cortisol-insensitive white blood cells had higher nasal levels of immune-signalling molecules that promote inflammation. The results suggest that stress induces cellular resistance to cortisol, reducing the body's ability to regulate inflammation - which is at the root of many diseases, including heart disease.

Proc. Natl Acad. Sci. USA 109, 5995-5999 (2012) arteries and showed that the cells can specialize into other cell types including smooth muscle and fat cells. To identify the origin of the dividing vascular cells, the authors fluorescently tagged smooth muscle cells in mice; they found, however, that the dividing vascular cells did not fluoresce but instead expressed stem-cell markers. Vascular cells isolated from an injured mouse carotid artery consisted mainly of these stem cells, suggesting that it is stem cells that divide upon injury, not smooth muscle cells.

Nature Commun. http://dx.doi. org/10.1038/ncomms1867 (2012)

\section{EVOLUTION}

\section{Monkey lips smack of speech}

Human speech could have evolved from monkey lipsmacking, an affectionate gesture that monkeys make towards each other.

Asif Ghazanfar at Princeton University in New Jersey, Tecumseh Fitch at the

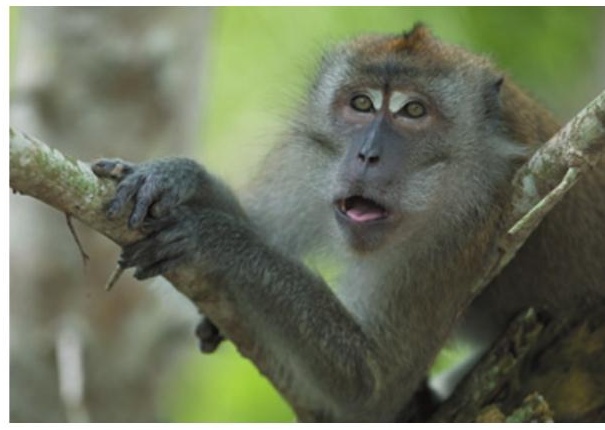

University of Vienna and their colleagues made X-ray movies of macaques during episodes of lip-smacking. The monkeys moved their lips five times per second - the same frequency as occurs in human speech, and much faster than when the monkeys chewed. Moreover, the monkeys' lip movements were independent of their throat movements during lipsmacking, much like human speech.

Curr. Biol. http://dx.doi. org/10.1016/j.cub.2012.04.055 (2012)

\section{$\rightarrow$ NATURE.COM}

For the latest research published by Naturevisit:

www.nature.com/latestresearch 